\title{
Social feeding in domestic chicks: Effects of food deprivation of nonfeeding companions'
}

\section{W. TOLMAN, University of Victoria, Victoria, B.C., Canada}

Five-day-old, 6-h-food-deprived cockeral chicks were tested for amount of feeding behavior when alone or when separated by Plexiglas from $0-h$, 6-h, or 24- $h$ fooddeprived companions (Cs), who either had food and were free to eat or had no food. The feeding of Ss varied positively with the food deprivation of $\mathrm{Cs}$ who could eat but not with that of noneating Cs. It was concluded that although $C s$ ' nonfeeding behavior may have a real facilitative effect upon Ss' feeding, the effects of Cs' food deprivation are mediated specifically by $\mathrm{Cs}^{\prime}$ feeding behavior.

It has been demonstrated that a chick's feeding behavior can be described as a function not only of his own food deprivation, but of the food deprivation of his feeding companion (Tolman \& Wilson, 1964; Tolman, 1968b). Presumably the critical factor operating here is the vigor of the companion's (C's) feeding behavior (Tolman, 1968a).

It has also been demonstrated recently that, although the mere presence of the $C$ is inadequate to bring about a facilitative effect upon S's feeding behavior, general activity or behavior other than feeding on the part of $C$ can have such an effect (Tolman, 1968b). Thus the question arises whether the effect of C's level of food deprivation upon $S$ is also mediated by behavior other than feeding. The present experiment was designed to answer this question by testing $6-\mathrm{h}$ food-deprived $\mathrm{Ss}$ in the presence of $0-h, 6-h$, and 24-h food-deprived $\mathrm{Cs}$ who could not eat.

\section{SUBJECTS}

Ninety-four white Leghorn cockerels obtained as day-olds from a local commercial hatchery were tested when 5 days of age. Water and food, a locally prepared chick starter mash, were continually available in the brooder except for the periods of food deprivation described below. A 6-W incandescent lamp in the $4 \mathrm{sq} f \mathrm{ft}$ brooder compartment provided constant illumination. Temperature was maintained at approximately $88 \mathrm{deg} \mathrm{F}$.
In all conditions except ISOL, C was placed into the observation compartment adjacent to S's, and thus was separated from him by a clear plastic partition. ${ }^{2}$ For $S s$ in all conditions and $\mathrm{Cs}$ where appropriate, food was spread evenly over the floor of the observation compartment forming a layer approximately $1 / 8 \mathrm{in}$. deep.

Test periods were $7 \mathrm{~min}$ in length. The dependent variable was the total number of food-directed pecks emitted by each $S$ during the test period.

\section{RESULTS}

The test apparatus was a rectangular observation box with clear plastic walls, $10 \times 18 \times 10 \mathrm{in}$. It was divided into two compartments of equal size by the insertion of a 3/32-in. clear plastic partition into vertical grooves in the side walls. The wood floor was finished in a gray enamel paint. Two 100-W desk lamps were placed between the Os and the test box, illuminating the observation areas from central points $12 \mathrm{in}$. above the floor of each of the two compartments. The temperature in the observation boxes was the same as that in the brooder, about $88 \mathrm{deg} F$.

\section{PROCEDURE}

All Ss were deprived of food 4 to $6 \mathrm{~h}$ prior to testing. Each was assigned to one of the following conditions:

ISOL: $\quad$ to be tested alone $(\mathrm{N}=10)$.

S/C0: to be tested with a 0 -h deprived $\mathrm{C}$ who had access to $\operatorname{food}(\mathrm{N}=6)$.

S/C6: to be tested with a 6-h deprived $\mathrm{C}$ who had access to food $(\mathrm{N}=10)$.

S/C24: to be tested with a 24-h deprived $\mathrm{C}$ who had access to food $(\mathrm{N}=6)$.

S/CNO: to be tested with a 0 -h deprived $\mathrm{C}$ who had no access to food $(\mathrm{N}=10)$.

S/CN6: to be tested with a 6-h deprived $\mathrm{C}$ who had no access to food $(N=10)$.

S/CN24: to be tested with a 24-h deprived $\mathrm{C}$ who had no access to food $(\mathrm{N}=10)$.

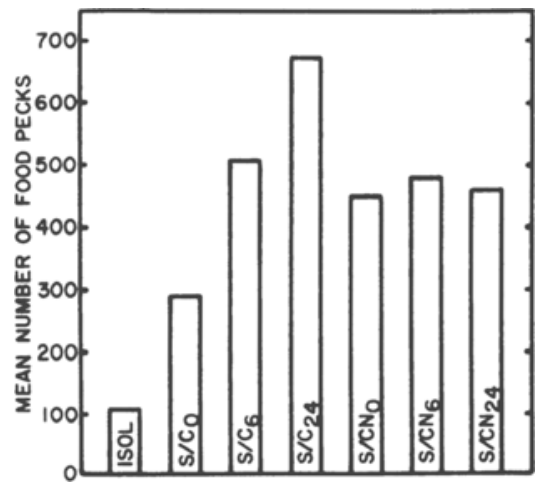

Fig. 1. Mean number of food pecks as a function of experimental condition.
The resulting group means are presented in Fig. 1. Analysis of variance showed a significant difference between ISOL and the other groups combined $(\mathrm{F}=40.38$, $\mathrm{df}=1 / 55, \mathrm{p}<.01)$. The differences among the groups with feeding $\mathrm{Cs}, \mathrm{S} / \mathrm{CO}, \mathrm{S} / \mathrm{C} 6$, and $\mathrm{S} / \mathrm{C} 24$, were also significant $(\mathrm{F}=7.93$, $\mathrm{df}=2 / 55, \mathrm{p}<.01)$. The differences among the groups with nonfeeding $\mathrm{Cs}, \mathrm{S} / \mathrm{CNO}$, $\mathrm{S} / \mathrm{CN} 6$, and $\mathrm{S} / \mathrm{CN} 24$, were not significant $(\mathrm{F}<1.00)$. The difference between the three $\mathrm{C}$ groups and the three $\mathrm{CN}$ groups was also not significant $(F<1.00)$.

\section{DISCUSSION}

The significant difference between ISOL and the remaining groups confirms earlier findings (e.g., Tolman, 1968a, b) and shows the facilitative effect of C upon S's feeding behavior. This result, together with the failure to find a difference between the combined $\mathrm{C}$ groups and combined $\mathrm{CN}$ groups, also confirms an earlier finding that $C$ need not be engaged in feeding behavior in order to have his facilitative effect. The earlier finding indicated that the effect did not occur when $C$ was completely inactive.

Also confirming earlier findings (Tolman \& Wilson, 1965), the feeding behavior of S was clearly affected by the food deprivation of $\mathrm{C}$ in those groups where $\mathrm{C}$ had access to food and thus could engage in feeding activity. Since, in the present results, such an effect did not occur in the groups where $\mathrm{C}$ had no access to food, it may be concluded that the facilitative effect upon $S$ of C's food deprivation is mediated by C's feeding behavior.

\section{REFERENCES}

TOLMAN, C. W. The role of the companion in social facilitation of animal behavior. In $\mathrm{E}$. Simmel, R. Hoppe, and G. Milton (Eds.), Social facilitation and imitative behavior. Boston: Allyn and Bacon, 1968a.

TOLMAN, C. W. The varieties of social stimulation in the feeding behaviour of domestic chicks. Behaviour, 1968b, 30, 275-286.

TOLMAN, C. W., \& WILSON, G.F.Social feeding in domestic chicks. Animal Behaviour., 1965, 13, 134-142.

\section{NOTES}

1. This work was supported by Grant APA 245 from the National Research Council of Canada.

2. For a discussion of this separated testing procedure see Tolman, $1968 \mathrm{~b}$. 